IZA DP No. 2426

Mergers of Equals and Unequals

Valerie Smeets

Kathryn lerulli

Michael Gibbs

November 2006 


\title{
Mergers of Equals and Unequals
}

\author{
Valerie Smeets \\ Universidad Carlos III de Madrid \\ and CCP \\ Kathryn lerulli \\ University of Chicago \\ Michael Gibbs \\ University of Chicago \\ and IZA Bonn
}

\section{Discussion Paper No. 2426 \\ November 2006}

\author{
IZA \\ P.O. Box 7240 \\ 53072 Bonn \\ Germany \\ Phone: +49-228-3894-0 \\ Fax: +49-228-3894-180 \\ E-mail: iza@iza.org
}

\begin{abstract}
Any opinions expressed here are those of the author(s) and not those of the institute. Research disseminated by IZA may include views on policy, but the institute itself takes no institutional policy positions.
\end{abstract}

The Institute for the Study of Labor (IZA) in Bonn is a local and virtual international research center and a place of communication between science, politics and business. IZA is an independent nonprofit company supported by Deutsche Post World Net. The center is associated with the University of Bonn and offers a stimulating research environment through its research networks, research support, and visitors and doctoral programs. IZA engages in (i) original and internationally competitive research in all fields of labor economics, (ii) development of policy concepts, and (iii) dissemination of research results and concepts to the interested public.

IZA Discussion Papers often represent preliminary work and are circulated to encourage discussion. Citation of such a paper should account for its provisional character. A revised version may be available directly from the author. 


\section{ABSTRACT}

\section{Mergers of Equals and Unequals}

We examine the dynamics of post-merger organizational integration. Our basic question is whether there is evidence of conflict between employees from the two merging firms. Such conflict can arise for several reasons, including firm-specific human capital, corporate culture, power, or favoritism. We examine this issue using a sample of Danish mergers. Controlling for other effects, employees from the acquirer fare better than employees from the acquired firm, suggesting that they have greater power in the newly merged hierarchy. As a separate effect, the more that either firm dominates the other in terms of number of employees, the better do its employees fare compared to employees from the other firm. This suggests that majority / minority status is also important to assimilation of workers, much as in ethnic conflicts. Finally, greater overlap of pre-merger operations decreases turnover. This finding is inconsistent with the view that workers of the two firms substitute for each other, creating efficiencies from merger. However, that result and our other findings are consistent with the view that more similar workers (in terms of either firm- or industry-specific human capital) are easier to integrate post merger.

JEL Classification: M5, G34, J63, M14

Keywords: mergers, internal organization, conflicts

Corresponding author:

Michael Gibbs

Graduate School of Business

University of Chicago

Chicago, IL 60637

USA

E-mail: mike.gibbs@gsb.uchicago.edu

\footnotetext{
* The data were provided by Statistics Denmark. All authors gratefully acknowledge generous funding and hospitality from the Center for Corporate Performance, Aarhus School of Business, Denmark. Gibbs gratefully acknowledges funding from the Otto Moensted Foundation. We thank Imran Rasul for very helpful comments, seminar participants at the WOO (Universidad Carlos III) and the CAFÉ Conference in Nuremberg. We also thank Mette Trier Damgaard for emergency research assistance.
} 


\section{Mergers of EquAls \& Unequals}

\section{INTRODUCTION}

A merger is a dramatic event in the life of a firm, for it requires the integration of two organizations into one. Indeed, the business press and management literature often argue that organizational integration is the most difficult hurdle to successfully completing a merger. There are at least two general sources of integration costs. First, explicit structures and policies must change. Second, implicit policies and social structures also need to evolve. This latter effect implies that workers are likely to be less productive when they have to work with colleagues who are more different from them. Thus, it generates both costs of changing the organization itself, and costs of decreasing productivity during transition.

An implication of merger is that organizational structures must be reconciled, including business units, geographical locations, and hierarchies. Occupational functions must be integrated, and overlap and redundancies managed. Human resource policies will probably have to be changed for at least one of the merging organizations, and possibly for both. Compensation levels and systems must be reconciled.

An additional cost of merger involves subtler and probably more difficult social integration issues. Managers and employees from each firm have different corporate cultures, different firm-specific human capital and may even come from different industries. They could have different personalities due to different hiring criteria. Individuals have developed personal networks of social relationships with colleagues, to increase communication and efficiency. These networks will have to evolve as the structure changes. Employees have implicit contracts with their employer, on the basis of which they provide effort, invest in human capital, and have ex- 
pectations about career prospects. When organizations merge, many of these factors must change.

There is therefore a strong possibility of organizational conflict, most especially between the employees of the two pre-merger firms. Such conflict of interests is also likely to generate favoritism for colleagues of one's former firm, only worsening the integration problem. Since these issues tend to draw lines between employees of the two former firms, a struggle similar to "ethnic conflict" may arise during the organizational integration. That, in turn, implies that the relative power of the two firms matters to how the merger plays out. For example, the more dominant (larger) firm may end up dominating the merged organization, just as majorities tend to dominate minorities in society. Similarly, employees from the acquiring firm may have greater power than those from the acquired firm, because the acquired firm tends to sell control rights to the acquirer.

Organizational integration post-merger has been studied in the social psychology literature (Haveman \& Cohen 1994; McEntire \& Bentley 1996; Stovel \& Savage 2005), but has not been studied much within economics. In this paper, we attempt to shed some light on this issue by studying a sample of firms that merged in Denmark during the 1980s and 1990s. By using matched worker-firm data for the entire Danish economy over this period, we are able to identify a reasonable number of mergers, and examine what happens post-merger to the employees from two firms that merge. We compare the post-merger turnover and wage growth of employees from the acquirer and acquired.

Overall, there is greater turnover and lower wage growth for acquired employees than for acquirer employees. This is consistent with the idea that the acquirer has greater power than the acquired firm post-merger, and suggests that the kind of "politics" that we consider in this paper do matter. We find that the more one firm dominates the other in terms of number of 
employees, the more successful are its employees post-merger. The majority does tend to drive out the minority after the merger, consistent with our notion of ethnic conflict between the two groups. Finally, when there is less overlap in operations between the two firms (different primary industry), there is greater turnover of both types of employees. This is inconsistent with economies of scope or scale, but is consistent with the view that the more organizational integration is more costly, the less similar the two merging firms are.

\section{THEORY}

We examine the effects of merger on the workforces of the acquirer and acquired firms. Most models of mergers generate at least implicit consequences for the total size of the merged firm, but few generate implications about the subsequent composition of the workforce. To think about these questions, we consider the role of belonging to the acquirer or acquired firm; the extent of overlap in operations between the two firms; and the extent to which one or the other dominates the merged enterprise. In our discussion, we refer to a merger of firms A (the acquirer) and B (the acquired).

\section{Acquirer v. Acquired Employees}

An empirical regularity in the small literature on the effects of merger on workers is that those from the acquirer fare better than those from the acquired firm (Brown \& Medoff 1988; Margolis 2003). Several possible models of post-merger organization generate this result. For example, suppose that A buys B to increase capacity (economies of scale). We would expect A to try to implement its own technology more than B's (since $\mathrm{A}$ is the acquirer). This implies that A's employees should be better adapted to the merged firm than B's, in terms of skills and firmspecific human capital. 
Alternatively, suppose that A buys B for governance. B has been allocating some rents to workers, perhaps in long-term contracts where at least some elements are implicit (Bertrand \& Mullainathan 2003). These contracts may or may not be ex ante optimal for B's management and workforce, but after the merger, A's management can expropriate some of the rents. Once more we would expect B's workers to fare relatively less well than A's post-merger (Shleifer \& Summers 1988).

These stories about differential treatment of workers from A and B lead to a similar conclusion, namely that workers from the acquiring firm have an advantage post-merger. More generally, if the acquiring firm has any advantage in power and governance after the merger, this result is likely. In our empirical work, we will examine how workers from the acquirer and acquired fare post merger, controlling for other factors.

\section{Dominance}

A merger of two organizations can be viewed as an assimilation problem, as in the ethnic conflict literature (see, e.g., Caselli and Coleman 2006, Monatalvo and Reynal-Querol 2005). Two groups must find a way to work together. A member of the dominant group finds it easier to fit in than a member of the minority group, so minority group members suffer. Might a similar effect occur in mergers? We present a simple model, based on Lazear (1996), to explore this idea.

Firms $\mathrm{X}$ and $\mathrm{Y}$ merge (either can be the acquirer). Consider a worker from firm $\mathrm{X}$, with skill $\lambda$ (which may include both innate abilities and accumulated human capital). The worker is paired with a colleague, c with skill $\lambda_{c}$. Output $Q$ is determined according to the production function $Q=\tau \cdot \lambda \cdot \lambda_{c}$, where $\tau$ is a shifter of production. A worker from firm $X$ can be paired with a colleague from firm $X$ or a colleague from firm $Y . g\left(\lambda_{c}\right)$ with the appropriate subscript $(X$ or $Y)$ 
represents the distribution of $\lambda$ among the relevant group of colleagues. Pay equals expected productivity.

Workers are more productive if they are paired with a colleague from the same firm, since the innate traits they were recruited for, their human capital investments, their culture, and their social network are more similar. This is modeled as $\tau(X)=1$ if the worker is paired with a colleague from the same pre-merger firm $X$, and $\tau(Y)<1$ if the worker is paired with someone from the merging firm $\mathrm{Y}$.

The probability that the worker is paired with colleague from same firm $=p(\Delta) \cdot{ }^{1}$ This probability depends on the relative number of workers from each firm. The larger is the worker's firm compared to the firm that it merges with, the more likely is it that the worker finds himself paired with a colleague from his original firm. Call this firm $X^{\prime}$ s dominance $(\Delta)$ over the other firm. A natural measure of dominance is the proportion of employees from that worker's firm:

$$
\Delta=\frac{\mathrm{N}_{\mathrm{X}}}{\mathrm{N}_{\mathrm{X}}+\mathrm{N}_{\mathrm{Y}}} .
$$

Thus, $\partial \mathrm{p} / \partial \Delta>0$.

Expected productivity $\overline{\mathrm{Q}}$ for a worker from firm $\mathrm{X}$ is:

$$
\begin{aligned}
\bar{Q} & =p \cdot \int \lambda \lambda_{c} g_{X}\left(\lambda_{c}\right) d \lambda_{c}+(1-p) \cdot \int \tau \lambda \lambda_{c} g_{Y}\left(\lambda_{c}\right) d \lambda_{c} \\
& =p \lambda \bar{\lambda}_{X}+(1-p) \tau \lambda \bar{\lambda}_{Y} .
\end{aligned}
$$

\footnotetext{
1 We do not model the pairing of colleagues. One extreme would be to pair colleagues with each other randomly, as in Lazear's model of ethnic assimilation. That is clearly unrealistic, since the firm would pair workers strategically to reduce conflict. All that we need for our argument is that a worker may be paired with a colleague from the other firm as a result of merger, and that the likelihood of such a pairing is lower, the more that the worker's firm dominates the merged firm.
} 
Productivity before the merger $=\lambda \bar{\lambda}_{X}$ is larger than $\overline{\mathrm{Q}}$ unless average productivity of workers at the other firm is much higher than it is at the worker's original firm. Therefore, productivity generally falls as a result of merger. This captures the idea that organizational integration is a cost of merger. The merger must have some other justification, such as economies of scale or scope, which we do not model since our interest is in the costs of organizational integration caused by merger.

Each worker has the option of working at the merged firm, or quitting and working elsewhere. Assume that workers earn quasi-rents at their pre-merger firm. If productivity falls after a merger, the probability of efficient worker turnover rises, since the wage equals expected productivity. Thus, comparative statics on $\overline{\mathrm{Q}}$ generate our empirical predictions about wages and turnover.

We can now see the effect of dominance on workers from each firm. Expected productivity is increasing in the extent that the worker's pre-merger firm dominates the other firm:

$$
\frac{\partial \bar{Q}}{\partial p}=\lambda \bar{\lambda}_{X}-\tau \lambda \bar{\lambda}_{Y}=\lambda\left(\bar{\lambda}_{X}-\tau \bar{\lambda}_{Y}\right)
$$

Unless expected productivity is much higher at the acquired firm, this expression is positive. Being a member of the dominant group improves expected productivity, because the worker is more likely to be well matched to the skills of his colleague. Similarly, being a member of the minority group reduces expected productivity. This prediction is quite similar to that in the ethnic conflict literature, where the dominant group is more successful and thus grows more dominant, and vice versa. It is also similar to tipping-point models of market share in industries with positive network externalities.

Therefore, we predict the following effects of dominance: the more dominant is the worker's pre-merger firm, the higher should be that worker's wage growth, and the lower 
should be turnover, post merger. If the worker is from a less dominant firm, wage growth should be lower, and turnover should be higher. These effects should hold for workers from both the acquired and acquirer firms. While workers from the acquirer may have an advantage, that advantage can be reinforced or attenuated to the extent that the acquirer is larger or smaller in size compared to the acquired firm.

\section{Overlap}

The discussion of dominance emphasizes the costs of integrating workers with different backgrounds. Dominance matters because differences in firm-specific human capital, corporate culture, personnel policies, and implicit contracts must be reconciled. An even more extreme integration problem occurs if the two firms operate in different industries. In that case, workers are likely to have industry-specific skills and human capital. Similarly, the more different the two businesses are, the more likely is it that explicit policies and implicit contracts are different. Thus, a merger of firms in different industries is likely to exacerbate the organizational conflict modeled above.

To see the effect of such overlap, assume now that firm $X$ operated in a single industry pre-merger, and firm $\mathrm{Y}$ operated in two industries, one of which was the same as firm X's industry. Thus there is some but not complete overlap of industry across the two firms. Workers who were employed in different industries are even more likely to be difficult to integrate with each other. Each group is likely to be more productive when paired with workers with similar backgrounds and training, which should be more similar if they have worked in the same industry prior to merger.

We can augment the model to account for this by breaking 1-p, the probability that the worker is paired with a colleague from firm $Y$, into the probability that the colleague in firm $Y$ is from the same industry $\left(\mathrm{q}_{\mathrm{s}}\right)$ and the probability that the colleague is from a different industry 
$\left(q_{d}\right)$. Thus $q_{s}+q_{d}=1-p$. In addition, let the shifter $\tau$ be a function of whether the colleague is from the same industry or a different one: $\tau=\tau(\bullet, \mathrm{s}$ or $\mathrm{d})$. If workers are less productive when paired with less similar colleagues, then $\tau_{\mathrm{s}}=\tau(\bullet, \mathrm{s})>\tau(\bullet, \mathrm{d})=\tau_{\mathrm{d}}$. Equation (1) becomes:

$$
\begin{aligned}
\bar{Q} & =p \cdot \int \lambda \lambda_{c} g_{X}\left(\lambda_{c}\right) d \lambda_{c}+q_{s} \cdot \int \tau(Y, s) \lambda \lambda_{c} g_{Y s}\left(\lambda_{c}\right) d \lambda_{c}+q_{d} \cdot \int \tau(Y, d) \lambda \lambda_{c} g_{Y d}\left(\lambda_{c}\right) d \lambda_{c} \\
& =p \lambda \bar{\lambda}_{X}+q_{s} \tau_{s} \lambda \bar{\lambda}_{Y s}+q_{d} \tau_{d} \lambda \bar{\lambda}_{Y d} .
\end{aligned}
$$

Less overlap between operations implies that $q_{s}$ is smaller. Since $q_{s}+q_{d}=1-p$, we have:

$$
\frac{\mathrm{d} \overline{\mathrm{Q}}}{\mathrm{dq}_{\mathrm{s}}}=\tau_{\mathrm{s}} \lambda \bar{\lambda}_{\mathrm{Ys}}-\tau_{\mathrm{d}} \lambda \bar{\lambda}_{\mathrm{Yd}}=\lambda\left(\tau_{\mathrm{s}} \bar{\lambda}_{\mathrm{Ys}_{\mathrm{s}}}-\tau_{\mathrm{d}} \bar{\lambda}_{\mathrm{Yd}}\right) \text {. }
$$

Once again, unless expected productivity is very different across the two comparison groups (colleagues from the same or different industry), we have an unambiguous result: expected productivity is lower, the smaller is the overlap between firms $\mathrm{X}$ and $\mathrm{Y}$. We therefore predict that less overlap (greater difference) between the firms' industries will imply lower wage growth and higher turnover.

This prediction derives from the view that integration of workers is less costly when they are more similar. However, there are likely to be other important factors in practice. For example, a merger of two firms from different industries may be based on a desire for economies of scope. If that is the case, then both types of workers may be needed to implement the new strategy (despite integration costs), resulting in lower turnover. Similarly, a merger of two firms in the same industry might imply economies of scale, resulting in excess workers and higher turnover. These economies of scope and scale effects would imply the opposite prediction: namely, that less overlap (greater difference) between the firm's industries will imply higher wage growth and lower turnover. Therefore, the actual effect of overlap or difference in operations is an open empirical question. However, finding that a merger of firms from differ- 
ent industries increases turnover would suggest that organizational conflict is an important issue in practice.

We have made predictions about the effects on the employee's wage growth and turnover of being from the acquirer or acquired firm; of the dominance of his pre-merger firm; and of difference or overlap in operations pre-merger. Many of our arguments are based on the importance of "politics" to organizational integration. It is interesting to note that favoritism (Prendergast \& Topel 1993, 1996) reinforces all of these predictions. All three effects imply that workers from A and B will to some extent be at odds with each other. That generates incentives for both types to exert favoritism for workers from their side. Such favoritism should be more successful for employees from the acquired firm, because their greater power gives them greater ability to play favorites. Therefore favoritism only reinforces any benefits to employees from the acquirer. Favoritism is also more likely to be exerted on behalf of a worker, if that worker is from the dominant group. Finally, workers may have some incentives to form alliances with those in the same industry (not just the same firm), if the post-merger firm involves several lines of business. This would reinforce any conflict created by less overlap in operations between the two firms. We now turn to the empirical analysis.

\section{DATA}

The data were provided by Statistics Denmark, the central statistics agency for the Danish government. Statistics Denmark maintains several databases that can be matched and merged. For the purposes of this paper, two databases were combined. First, from an annual database of all Danish firms collected each November, a sample of private sector firms from 1980 through 2001 was constructed. Those data include establishment codes for each business location within the firm, and the industry that each establishment is in. Information on estab- 
lishments was used to define the sample of merged firms. Unfortunately, data on financial or business performance of firms is not available from Statistics Denmark, so we are unable to analyze the performance of the firms before or after merger (except by looking at employment growth).

Second, the firm data were matched with information on all employees in each establishment, collected by Statistics Denmark each November. Data on individuals includes education and occupation codes, age, gender, wages, and experience. ${ }^{2}$ Since individual identification codes do not change when a worker changes a firm or leaves the labor market, we were able to measure tenure with the employee's current employer.

\section{Identifying Mergers}

The Statistics Denmark database does not flag mergers, so the first step was to identify a merger sample through inference. ${ }^{3}$ This was done by looking for cases where establishments from the same firm changed their firm code number from one year to the next. This was possible because establishment codes did not change if an establishment changed ownership from one firm to another. Therefore, it was possible to follow workplaces as they changed ownership over time. There are several possibilities:

- A firm changed its name / code number. This would be a case in the data where all (or almost all) establishments in a single firm changed to a new firm code in the same year, but no establishments from any other firm changed to the new firm code at the same time. Such cases were rare, and dropped from the sample.

- Two or more firms merged together to form a new firm. This would be a case where all (or almost all) establishments from two or more firms changed to the same new firm code in the same year. For example, firms A and B might merge together, forming the new en-

\footnotetext{
${ }^{2}$ Labor market experience since 1964 is calculated by Statistics Denmark and truncated at that date.

${ }^{3}$ Hostile takeovers are virtually unheard of in Denmark.
} 
tity $\mathrm{C}$. These were quite easy to identify in the data, since a new firm code appeared and typically the old firm codes disappeared (though it is possible that some vestigial part of A or B remained outside of $C$ ).

- A firm merged with part or all of one or more other firms, but retained its name. This would be a case where all (or almost all) establishments from one or more firms changed to the same existing firm code in the same year. For example, part or all of firms B and C might merge with all of $\mathrm{A}$, with the merged firm called A.

The set of mergers was narrowed further to the most unambiguous examples. First, our sample was filtered to include only mergers for which two years of prior data was available for both firms pre-merger, and three years of data for the post-merger firm (thus limiting our sample to mergers taking place from 1982 through 1998). This enables us to study the dynamics of employees pre- and post-merger. Second, we dropped cases where a firm went through more than one merger during the sample window. Third, all mergers where one or both pre merger firms had less than 5 employees were dropped. This left a sample of 640 mergers.

A final step was the identification of the acquirer and acquired firms. This was obvious for mergers where firm A absorbed all or part of firm B, with the resulting firm still called A (the majority of cases; see Table 1). Where firms A and B combined to form C, we identified the acquirer as the firm A that contributed the largest number of employees to the combination in the year of merger.

\section{Summary Statistics}

Table 1 provides initial summary statistics. There are three types of mergers: A acquires all of $\mathrm{B}$ and the merged firm is called $\mathrm{A} ; \mathrm{A}$ and $\mathrm{B}$ merge to form a new firm $\mathrm{C}$; and $\mathrm{A}$ acquires only part of B, with the result called A. By far, the first type is the most common, comprising over $80 \%$ of cases. The other types each comprise about $8 \%$ of the cases. As seen in the table, the 
number of mergers per year is roughly stable except for 1991; there is little evidence of macroeconomic effects on mergers in Denmark.

Table 2 provides information on the characteristics of employees from acquirer firms, acquired firms, and a control group, in the year before the merger. Previous studies (Margolis 2003) found some differences in the demographics of employees from each firm. In our Danish sample, employees look virtually identical in the two source firms. Acquirer employees earn more per hour, and are a little more likely to have a college degree, but both differences are slight. Acquirer employees are also more likely to work full time (defined as 37.5 or more hours per week) by a non-trivial margin, and have a little more tenure at their firms. Overall, there is little indication that Danish firms merge for reasons having to do with differences in the two labor forces. We report the result of t-tests for differences in means between acquirer and acquiring firms; the aforementioned variables have significant differences in means, but the rest do not.

Comparing the characteristics of acquirer and acquired firms to a sample of nonmerging Danish firms, ${ }^{4}$ merging firms are rather similar to non-merging firms. The merging firms are larger and have slightly older and more educated workers than the non-merging sample, but the differences, apart from firm size, are small. Finally, Table 2 shows the distribution of modal 1-digit industry (by number of employees) for the firms in the year of merger. Most of the mergers are in either service or manufacturing industries.

In examining turnover in acquired and acquiring firms post-merger (Table 3), it is worth noting the high level of turnover of the Danish labor market generally. ${ }^{5}$ There are several Dan-

\footnotetext{
4 The control group of non-merging firms was constructed as follows: Danish private sector firms with greater than or equal to 5 employees, observed over the same time period (1981-97) as our pre merger firms.

5 Turnover in Denmark is high partly because a number of transitions are included in the official statistics: transitions between work and education, job training, and generous family leave are all included, as well as the many transitions
} 
ish labor market policies that support this level of turnover. The Danish government provides extensive benefits and unemployment insurance to Danish workers if they leave their job, including up to $90 \%$ of their earnings. Moreover, Danish firms are required to provide only one day of severance pay. Thus, the explicit turnover costs to both workers and firms are very low in Denmark, resulting in turnover per year of averaging $27 \%$ of a firm's workforce. As we see in Table 3, post-merger turnover is high in our sample, but typical for Danish firms. In the year after the merger, acquirer and acquired workers leave at $20.4 \%$ and $24.8 \%$ respectively - substantial, but still less than the Danish average. Interestingly, turnover at the acquired firm is higher the year before the merger, at $31.3 \%$, and a bit lower at the acquirer, at $24.5 \%$. This suggests that either the acquired firm may be undergoing some form of internal reorganization just before the merger or that workers from the acquired firm may react to the possibility of a merger by leaving before the merger actually takes place. The post-merger turnover continues this pattern, with turnover at the acquirer lower at $20.4 \%$, and turnover at the acquired relatively higher at $24.8 \%$.

Based on the theory above, we constructed the variable dominance (of the acquirer), which equals the number of workers from the acquirer divided by the total number of workers from the acquirer and acquired firms at the time of merger:

$$
\text { Dominance }=\frac{\# \text { of employees from acquirer }}{\# \text { from acquirer }+\# \text { from acquired }}
$$

This is a straightforward measure of the extent to which the new workforce will be dominated by employees from the acquirer. Typically, this fraction is above $50 \%$, since the acquirer is usually larger than the acquired firm. In thinking about the empirical results, it is important to keep

between part-time employment and any of the previous states (over two-thirds of Danes work part-time, many at more than one part-time job). See Westergaard-Nielsen (2002). 
in mind that the model predicts the effects of dominance of the employee's firm, but in the empirical work dominance is measured for the acquirer. Therefore, for employees of the acquired firm, if the variable dominance is higher, that means that their pre-merger firm is less dominant.

Table 4 provides summary statistics on dominance. In the table, the sample is divided into dominance tertiles, where the first tertile is the third of the sample with the smallest degree of dominance of the acquirer over the acquired firm. The first panel shows statistics on the distribution of the dominance measure by dominance tertile. Not surprisingly, mergers with greater dominance of acquired over acquirer are more likely to have larger acquirers, and smaller acquired firms. The second panel provides information on the number of employees of the acquirer and acquired firms by dominance tertile. On average, a merger has about twothirds of its employees from the acquirer and one-third from the acquired. However, extreme cases are observed, where almost all employees come from either the acquirer or acquired firm. In the lowest dominance tertile, some mergers are observed where the acquired firm dominates post-merger employment.

To proxy for the difference in operations between the two firms pre-merger (lack of overlap), we defined the dummy variable difference in industry, equal to one if the modal industry for employees from both firms is different at the time of merger, and zero if the modal industry is the same. Table 5 provides summary statistics on the measure of difference in industry between acquirer and acquired. What is clear from the table is that mergers of firms that primarily operate in different 1- or 2-digit industries are not typical. Rather, $80-90 \%$ of all mergers are between firms with the same modal industry. Additionally, we see that the difference in industry decreases significantly $-6.4 \%$ at the 1 -digit level or $7.1 \%$ at the 2 -digit level - between the pre-merger and merger period. This is suggestive of some degree of reorganization before the 
merger on the part of one or both firms, as was seen in the pre-merger turnover statistics from Table 3, and of post-merger consolidation into the modal industry.

\section{RESULTS}

\section{Probits}

The main findings are presented in Tables 6,7 and 8 . Table 6 considers turnover, while Table 7 considers wage growth, each for one year and three years following the merger.

Table 6 presents four turnover probits in the year following the merger, two each for employees from the acquirer and acquired firms. The first probit estimates the probability that the employee leaves from year 0 to year 1 post-merger, the second that the employee leaves from year 0 to year 3 . There is a distinct difference in predicted turnover rates for the two types of employees at the year after merger: $17 \%$ of employees from the acquirer leave that year, while $22 \%$ leave from the acquired firm. The three-year predicted turnover rate is also higher for acquired workers - $51 \%$, compared to $41 \%$ of acquirer workers.

The first explanatory variable in the probits is the degree of dominance by the acquirer over the acquired. For acquired workers, both the one- and three-year probits indicate that turnover is larger, the greater is the degree of dominance, with the three-year effect substantially larger than the one-year effect. On the other hand, dominance reduces turnover of acquirer workers, though only the three-year effect is significant. This finding is difficult to explain with simple stories of economies of scale and scope, which have nothing to do with the internal composition of the combining firms. Instead, this finding is more consistent with the idea that composition of the firm - and potential conflict between the two source firms - plays an important role in subsequent turnover. There are conceptually two effects. First, the more asymmetric the merger, the weaker the relative position of employees from the acquired firm, 
as the firm culture is more representative of the acquirer. Second, the more similar the employees of the merged firm, the more productive they are. Both effects might be captured in our dominance variable.

Summarizing the results for dominance, we see the predicted effect: dominance increases turnover of acquired workers and decreases turnover of acquirer workers. Of particular interest is that the effects of dominance on increasing turnover for acquired employees are larger and more significant than on decreasing turnover for acquirer employees. This provides evidence that acquirer employees may have greater power than acquired employees.

Turning to the industry difference variable, if the two firms do not have the same modal industry (industry difference equals 1), turnover is higher for both the acquirer and the acquired firm's employees. This makes sense for two reasons. First, it is more difficult to integrate the firm when the production processes of acquirer and acquired are different. Second, the employees are poorer substitutes for each other. Note, though, that the effect is twice as large for acquired employees as for acquirer employees in the three-year probits. This is more evidence that merger affects the two groups of employees quite differently, and that those from the acquirer are at an advantage over acquired employees.

A different conclusion emerges from the coefficient on whether the merger was "type 3" or not. A type 3 merger is one in which firm A merges with part, but not all, of firm B. In such a case, it is likely that firm A has not merged with the top management of firm B, and so organizational conflicts may be less intense. We think of this type of merger as cherry-picking, where A chooses only a part of B to merge with, presumably that part which complements A's strengths. If so, then firm B's employees are not at a disadvantage compared to those from the acquirer firm. Indeed, the coefficients are similar in size for both acquirer employees and acquired employees. Both experience reduced turnover in this type of merger. 
The probits in Table 6 contain controls that are typically included in turnover analyses. Turnover is lower for those who have more experience and tenure with their firm at the time of merger. The greater the level of education, the less likely is the employee to leave the merged firm. This may suggest that employees at higher hierarchical levels are more shielded from losing their jobs because of the merger. Finally, there is little effect of wage level on likelihood of turnover. This addresses the relevance of the model of merger for governance, since it indicates that economies from fixing previously inefficient (too high) compensation levels do not seem to be an important motivation for Danish mergers (Bertrand \& Mullainathan 2003; Margolis 2003).

Table 7 presents regressions with wage growth as the dependent variable. We regard these as a check of the robustness of the dominance measure to our story of differential treatment of acquirer and acquired workers - there is reason to be skeptical of Danish firms' ability to adjust wages. Scandinavian firms often engage in industry-wide wage bargaining with unions (which cover large fractions of the workforce), and Danish firms tend to have a relatively high degree of wage compression. Looking first at the constant terms, acquirer workers do a bit better than acquired workers in wage growth, both for the one- and three-year comparisons. The dominance variable reduces wage growth for both acquirer and acquired in the one-year probits, and for acquired workers at in the three-year probit. The sign and magnitude of the coefficients on dominance reinforce the perception of acquirer workers faring better post merger as dominance increases. However, we do not place much emphasis on the wage results because of the institutional considerations just mentioned. We now return to turnover effects.

To control for the fact that observations might not be necessarily independent within groups (in our case mergers), we estimate turnover probits similar to Table 6 where standard 
errors are clustered at the merger-year level. Results are presented in Table 86 . For acquired workers, the effect of dominance is similar to what we found in previous estimations, both one year and three years after the merger. We see this as an important validation of the robustness of the effect of dominance on acquired workers. However, the small effect we had for acquirer workers vanishes once we cluster standard errors7

To test the robustness of our dominance result, we also tried other specifications of postmerger turnover. First, we add interactions between individual characteristics of workers as age, education, female and tenure at the pre-merger firm with the dominance and industry difference variables to check whether some specific groups were more targeted than others. However, in most of the specifications, the interactions were not significant and in the few cases where they were, the magnitude of these effects was very slight. However, none of these specifications did affect the magnitude of the effect of dominance on post-merger turnover. Second, we add pre-merger turnover (measured as one year before the merger) to control for potential internal reorganization prior a merger. While we found a positive and significant relationship between pre- and post-merger turnover, the effect and the magnitude of the dominance variable was unaffected.

\section{Nonlinearities}

Up to now, our results have shown that dominance strongly affects the fate of workers after a merger, especially workers belonging to the acquired firm. However, our previous estimations have relied on the assumption that such a relationship would be linear. In what fol-

\footnotetext{
6 The reason why coefficients slightly vary between Table 6 and Table 8 is that specifications from Table 6 include year dummies while specifications from Table 8 do not.

7 In addition, note that the other merger variables (industry difference and merger type 3) become insignificant with clustered standard errors. One possible explanation is that - as these variables are defined as dummy variables - there is not enough variation to get a significant effect once we cluster standard errors.
} 
lows, we use a semi-parametric approach to investigate whether post-merger turnover and dominance of the acquirer at the time of the merger exhibit a non linear relationship.

To test for non linearity of dominance, we estimate the following model:

$$
\text { Turnover }_{i t}=f(\text { Dominance })+\beta \cdot z_{i t}+\varepsilon_{i t},
$$

where $\mathrm{z}_{\mathrm{it}}$ are the covariates used in the previous estimations. ${ }^{8}$ We rely on a semi-parametric two steps procedure to obtain estimates of the coefficients $\beta$ and an estimate of the function $f^{9}$. The first step consists of retrieving the partial residuals from an estimation of post-merger turnover and dominance on $\mathrm{z}_{\mathrm{it}}$. The second step estimates non parametrically the relationship between the residuals of post-merger turnover and dominance. As dominance affects acquirer and acquired workers differently, both in the short and long run, we estimate the model on four subsamples: acquirer workers 1 and 3 years after the merger, and acquired workers 1 and 3 years after the merger. The semi-parametric estimations of post-merger turnover on dominance are presented in Figure 1.

The graphs plot the standardized residuals of post-merger turnover as a function of the residuals of dominance. We see that the results from the semi-parametric estimation strongly support our probit results. For acquired workers, the residuals from turnover estimation are increasing in residuals from dominance estimation, and the effect is quite marked after three years. Compare these figures for acquired to those of acquirer: after three years, there is a negative relationship between the residuals of turnover to residuals of dominance for the acquirer.

\footnotetext{
8 The covariates are industry difference, merger type 2 or 3 , female, three educational groups, full time, hourly wage, merger size, and quadratics on age, experience, and tenure.

${ }^{9}$ We use the following semi-parametric procedure to estimate $f$ in the model $y_{i}=f\left(x_{i}\right)+\beta \cdot z_{i t}+\varepsilon_{i t}$. First, we regress y and $\mathrm{x}$ on $\mathrm{z}$ and compute the residuals, say $\varepsilon_{\mathrm{x}}$ and $\varepsilon_{\mathrm{y}}$. For the estimation of $\mathrm{y}$ on $\mathrm{z}$, we run a probit estimation and compute the standardized residuals, while for the estimation of $x$ on $z$, we use an OLS estimation. Second, we perform a non-parametric estimation of $\varepsilon_{\mathrm{y}}$ on $\varepsilon_{\mathrm{x}}$. We rely on lowess smoothing, which involves running a separate smoothing regression of $\varepsilon y$ on $\varepsilon x$ for each value of $\varepsilon y$, meaning that a separate smoothing regression is run for each data point. The estimates plotted in Figure 1 use a bandwidth equal to 0.8 .
} 
It is interesting to note that the shape of the relationship becomes steeper with dominance. There seems to be a turning point after which acquired workers face a higher marginal probability of post-merger turnover. The effect is mild in the short run (bottom left panel) but dramatic in the long run (bottom right panel). For acquirer workers, the effect is reverse: after the turning point, workers enjoy a lower marginal probability of post-merger turnover, but only on the long run (top right panel). It is interesting to note that both turning points are located very close to the middle of the dominance axis. These graphs indicate that post-merger turnover and dominance exhibit a non linear relationship which becomes stronger once a given level of dominance is attained.

\section{CONCLUSION}

Mergers are difficult and costly to implement. Management often faces (or chooses) sweeping changes in production, composition of its labor force, financing, product markets, organizational design, compensation schemes, and the nebulous but critical element called 'corporate culture.' The focus here has been the effect on workers of this large disruption, and how these effects vary from acquiring to acquired firms with respect to dominance of acquiring firms. We posit two general kinds of effects. One is that workers who are more different from each other are likely to be less productive colleagues, because of differences in personality, human capital, etc. The second is that different factions - acquiring workers being one faction, and acquired workers the other - may have incentives to work against each other and for their own group. This second effect reinforces the first effect.

Due to the unusually complete longitudinal data from Statistics Denmark, we can follow firms and individuals before and after mergers. We focus on the effects of being from the acquirer or acquired firm, dominance of one firm over the other, and differences in industry be- 
tween two firms. We measure the effects on both wage growth and turnover. Because Denmark has such centralized and compressed wage policies, we find little effect on wages. However, there are clear effects on turnover.

We find that employees from the acquirer fare better, all else equal, than those from the acquired firm. That result is consistent with the prior literature on the employment effects of merger. It suggests that the acquirer firm A has greater power (presumably derived from control rights negotiated at merger), which it uses to implement a merged organization more similar to A than to firm B, and to play favorites for its own workers.

Our second finding is more novel: employees from the firm that dominates in size (which could be the acquired firm) tend to fare better post merger. This is evidence that workers from the minority firm are at a disadvantage after merger, perhaps because their human capital is not a good fit for the new organization, which is more oriented toward the dominant firm's original design. It may also be a sign that workers from both firms engage in something like ethnic conflict with each other.

Our third finding is that if the merged firms had different modal industries pre-merger, turnover is higher. This is not consistent with the simple view that economies of scope and scale drive employment effects of merger. However, it is consistent with the idea that organizational integration is more difficult, the more different workers are before the merger. That could be driven by lower productivity when workers from different backgrounds work together, or an additional dimension of factionalism and favoritism, or both.

Our results tell a consistent story: organizational integration and the politics associated with it are costly. We find that mergers increase turnover, and our results are not consistent a simple story in which this turnover is caused by economies of scope and scale. Rather, the results all suggest that integration of different types of employees is costly in and of itself. The 
finding that acquired employees are treated differently than acquirer employees, along with the other patterns found, strongly suggests that at least some of this is due to organizational "politics," and not just lower marginal productivity of pairing workers of different types. 


\section{REFERENCES}

Bertrand, Marianne \& Sendhil Mullainathan (2003). “Enjoying the Quiet Life? Corporate Governance and Managerial Preferences." Journal of Political Economy October: 1043-1075.

Brown, Charles \& James Medoff (1988). "The Impact of Firm Acquisition on Labor." In Alan J. Auerbach, ed., Corporate Takeovers: Causes and Consequences. Chicago: University of Chicago Press, 1988.

Caselli, Francesco \& William John Coleman II. "On the Theory of Ethnic Conflict." Working Paper, London School of Economics, 2006.

Haveman, Heather \& Lisa Cohen (1994), "The Ecological Dynamics of Careers: the impact of organizational founding, dissolution and merger on job mobility." American Journal of Sociology 100: 104-152.

Lazear, Edward (1999). “Culture and Language." Journal of Political Economy 107(6 part 2): S95S126.

Margolis, David (2003). “Compensation Policy, Human Resource Management Practices, and Takeovers." Working paper, CNRS, TEAM-Universite Paris 1.

Montalvo, Jose G. \& Marta Reynal-Querol (2005). “Ethnic Polarization, Potential Conflict, and Civil Wars." American Economic Review 95(3): 796-816.

McEntire, Marjorie and Joseph Bentley (1996), “When Rivals Become Partners: Acculturation in a Newly-Merged Organization." International Journal of Organizational Analysis 4(2): 154-174.

Prendergast, Canice \& Robert Topel (1993). “Discretion and Bias in Performance Evaluation." European Economic Review 37(2-3): 355-365.

Prendergast, Canice \& Robert Topel (1996). “Favoritism in Organizations." Journal of Political Economy 104(5): 958-978.

Shleifer, Andrei \& Lawrence Summers (1988). "Breach of Trust in Hostile Takeovers." In Alan J. Auerbach, ed., Corporate Takeovers: Causes and Consequences. Chicago: University of Chicago Press, 1988.

Stovel, Katherine \& Mike Savage (2005). “Mergers and Mobility: Organizational Growth and the Origins of Career Migration at Lloyds Bank.” American Journal of Sociology 111(4).

Westergaard-Nielsen, Niels (2002). "20 Years of Labour Market Policies in Denmark.” In Ilmakuunas, S. and E. Koskela (eds.), Towards Higher Employment, Helsinki: Government Institute for Economic Research. 
TABLE 1 - Merger Summary Statistics

\begin{tabular}{c|c|c}
\hline Merger type & $\mathrm{N}$ & $\%$ \\
\hline A acquires all of B & 539 & 84.2 \\
A \& B combine in new firm & 50 & 7.8 \\
A acquires part of B & 51 & 8.0 \\
\hline
\end{tabular}

\begin{tabular}{c|c|c}
\hline Year of the merger & $\mathrm{N}$ & $\%$ \\
\hline 1982 & 25 & 3.9 \\
1983 & 26 & 4.1 \\
1984 & 30 & 4.7 \\
1985 & 22 & 3.4 \\
1986 & 24 & 3.8 \\
1987 & 29 & 4.5 \\
1988 & 40 & 6.3 \\
1989 & 25 & 3.9 \\
1990 & 36 & 5.6 \\
1991 & 87 & 13.6 \\
1992 & 52 & 8.1 \\
1993 & 34 & 5.3 \\
1994 & 36 & 5.6 \\
1995 & 43 & 6.7 \\
1996 & 49 & 7.7 \\
1997 & 43 & 6.7 \\
1998 & 39 & 6.1 \\
\hline
\end{tabular}


TABLE 2 - Summary Statistics of Acquirers, Acquired and Non Merging Firms

\begin{tabular}{|c|c|c|c|c|c|c|c|}
\hline \multirow{2}{*}{ Variable } & \multicolumn{2}{|c|}{ Acquired } & \multicolumn{2}{|c|}{ Acquirer } & \multirow{2}{*}{$\begin{array}{c}\neq \text { in } \\
\text { means }\end{array}$} & \multicolumn{2}{|c|}{ Non Merging Firm } \\
\hline & Mean & Std. Dev. & Mean & Std. Dev. & & Mean & Std. Dev. \\
\hline Hourly wage (kroner) & 114.8 & 40.7 & 123.6 & 52.8 & $Y$ & 111.3 & 49.3 \\
\hline$\%$ Female & 37.8 & 30.1 & 37.9 & 26.8 & $N$ & 35.2 & 29.1 \\
\hline Age & 34.6 & 7.0 & 35.0 & 6.7 & $N$ & 33.5 & 7.2 \\
\hline Experience & 11.0 & 4.9 & 11.3 & 4.6 & $N$ & 9.6 & 4.7 \\
\hline Tenure & 3.9 & 3.0 & 4.3 & 3.0 & Y & 3.4 & 2.8 \\
\hline Years of schooling & 11.1 & 1.1 & 11.2 & 1.1 & $N$ & 10.9 & 1.1 \\
\hline$\%$ college \& masters & 6.6 & 13.6 & 8.4 & 14.2 & $Y$ & 5.1 & 11.8 \\
\hline$\%$ vocational & 49.6 & 22.3 & 48.4 & 19.1 & $N$ & 47.9 & 22.7 \\
\hline$\%$ community college & 3.1 & 6.8 & 3.2 & 5.7 & $N$ & 2.6 & 6.2 \\
\hline$\%$ full-time & 32.2 & 24.1 & 34.4 & 22.8 & $Y$ & 33.7 & 24.2 \\
\hline Firm size & 36.6 & 150.1 & 128.7 & 361.6 & Y & 28.1 & 189.3 \\
\hline Industry $(\%)$ & \multicolumn{5}{|c|}{ Merger } & \multicolumn{2}{|c|}{ Non Merging Firm } \\
\hline Retail, hotels \& restaurants & \multicolumn{5}{|c|}{43.6} & \multicolumn{2}{|c|}{37.5} \\
\hline Manufacturing & \multicolumn{5}{|c|}{30.3} & \multicolumn{2}{|c|}{23.3} \\
\hline Finance, real estate, $R \& D$ & \multicolumn{5}{|c|}{14.4} & \multicolumn{2}{|c|}{12.8} \\
\hline Construction \& transport & \multicolumn{5}{|c|}{10.2} & \multicolumn{2}{|c|}{21.9} \\
\hline Agriculture \& mining & \multicolumn{5}{|c|}{1.4} & \multicolumn{2}{|c|}{4.1} \\
\hline Other & \multicolumn{5}{|c|}{0.2} & \multicolumn{2}{|c|}{0.4} \\
\hline $\mathrm{N}$ & \multicolumn{5}{|c|}{640} & \multicolumn{2}{|c|}{671,939} \\
\hline
\end{tabular}


TABLE 3 - Turnover Rate for Merging and Non Merging Firms (\%)

\begin{tabular}{l|c|c|c}
\hline \hline \multicolumn{4}{c}{ All Danish Firns } \\
\hline Turnover & over 1 year & \multicolumn{2}{c}{27.1} \\
\hline \multicolumn{4}{c}{ Merging firms } \\
\hline Pre merger turnover & over 1 year & 31.3 & 24.5 \\
\hline \multirow{3}{*}{$\begin{array}{c}\text { Cumulative post } \\
\text { merger turnover }\end{array}$} & over 1 year & 24.8 & 20.4 \\
& over 3 years & 39.4 & 32.3 \\
\hline \hline
\end{tabular}


TABLE 4 - Dominance of Acquirer over Acquired

\begin{tabular}{|c|c|c|c|c|c|c|}
\hline & & & \multicolumn{3}{|c|}{ Dominance Tertile } & \multirow{2}{*}{ Overall } \\
\hline & & & 1 & 2 & 3 & \\
\hline \multirow{4}{*}{$\begin{array}{c}\text { Degree of } \\
\text { dominance }\end{array}$} & \multirow{4}{*}{$\begin{array}{l}\text { (\# employees from } \\
\text { acquirer / \# from } \\
\text { acquirer \& acquired) }\end{array}$} & mean & 0.36 & 0.69 & 0.89 & 0.65 \\
\hline & & std. dev. & 0.16 & 0.06 & 0.06 & 0.24 \\
\hline & & $\min$ & 0.01 & 0.57 & 0.79 & 0.01 \\
\hline & & $\max$ & 0.57 & 0.79 & 0.99 & 0.99 \\
\hline \multirow{4}{*}{$\begin{array}{l}\text { \# of employees } \\
\text { from }\end{array}$} & \multirow{2}{*}{ Acquirer } & mean & 32.8 & 84.4 & 268.9 & \\
\hline & & std. dev. & 72.7 & 153.0 & 616.7 & \\
\hline & \multirow{2}{*}{ Acquired } & mean & 53.6 & 36.0 & 20.3 & \\
\hline & & std. dev. & 115.6 & 65.1 & 31.6 & \\
\hline & & $\mathrm{N}$ & 211 & 218 & 211 & 640 \\
\hline
\end{tabular}


TABLE 5 - Difference of modal industry between Acquirer and Acquired

\begin{tabular}{c|c|c|c|c|c|c}
\hline \hline \multicolumn{2}{c|}{} & \multicolumn{2}{c|}{ 1-digit industry } & \multicolumn{2}{c}{ 2-digit industry } \\
\hline \multirow{3}{*}{$\begin{array}{c}\text { Modal industry is } \\
\text { different }\end{array}$} & $\begin{array}{c}\text { before the } \\
\text { merger }\end{array}$ & yes & 116 & 18.1 & 150 & 23.4 \\
& & no & 524 & 81.9 & 490 & 76.6 \\
& at the & yes & 75 & 11.7 & 104 & 16.3 \\
& merger & no & 565 & 88.3 & 536 & 83.8 \\
\hline \hline
\end{tabular}


TABLE 6 - Post Merger Turnover (Probit estimation)

\begin{tabular}{|c|c|c|c|c|}
\hline \multirow{2}{*}{$\begin{array}{l}\text { Dept. Variable: } \\
\text { Post Merger Turnover }\end{array}$} & \multicolumn{2}{|c|}{ Acquired Employees } & \multicolumn{2}{|c|}{ Acquirer Employees } \\
\hline & $\begin{array}{l}1 \text { year } \\
\text { turnover }\end{array}$ & $\begin{array}{l}3 \text { years } \\
\text { turnover }\end{array}$ & $\begin{array}{l}1 \text { year } \\
\text { turnover }\end{array}$ & $\begin{array}{l}3 \text { years } \\
\text { turnover }\end{array}$ \\
\hline Dominance of A over B & $\begin{array}{l}0.100^{* * *} \\
(0.0127)\end{array}$ & $\begin{array}{l}0.301^{* * *} \\
(0.016)\end{array}$ & $\begin{array}{l}-0.006 \\
(0.010)\end{array}$ & $\begin{array}{l}-0.023^{*} \\
(0.013)\end{array}$ \\
\hline Industry Difference & $\begin{array}{c}0.001 \\
(0.010)\end{array}$ & $\begin{array}{l}0.067^{* * *} \\
(0.012)\end{array}$ & $\begin{array}{l}0.051^{* * *} \\
(0.006)\end{array}$ & $\begin{array}{c}0.032^{* * *} \\
(0.007)\end{array}$ \\
\hline Merger type 2 & $\begin{array}{l}-0.010 \\
(0.312)\end{array}$ & $\begin{array}{l}-0.005 \\
(0.013)\end{array}$ & $\begin{array}{c}0.006 \\
(0.007)\end{array}$ & $\begin{array}{l}-0.004 \\
(0.009)\end{array}$ \\
\hline Merger type 3 & $\begin{array}{l}-0.023^{* *} \\
(0.011)\end{array}$ & $\begin{array}{c}-0.080 * * * \\
(0.014)\end{array}$ & $\begin{array}{c}-0.031^{* * *} \\
(0.004)\end{array}$ & $\begin{array}{c}-0.070 * * * \\
(0.006)\end{array}$ \\
\hline Age & $\begin{array}{c}-0.019 * * * \\
(0.002)\end{array}$ & $\begin{array}{c}-0.046^{* * *} \\
(0.003)\end{array}$ & $\begin{array}{c}-0.019 * * * \\
(0.001)\end{array}$ & $\begin{array}{c}-0.052^{* * *} \\
(0.001)\end{array}$ \\
\hline Age $^{2}$ & $\begin{array}{c}0.0003^{* * *} \\
(0.0000)\end{array}$ & $\begin{array}{l}0.001^{* * *} \\
(0.0000)\end{array}$ & $\begin{array}{l}0.0003^{* * *} \\
(0.0000)\end{array}$ & $\begin{array}{l}0.001^{* * *} \\
(0.0000)\end{array}$ \\
\hline Experience & $\begin{array}{c}-0.011^{* * *} \\
(0.002)\end{array}$ & $\begin{array}{c}-0.019 * * * \\
(0.002)\end{array}$ & $\begin{array}{c}-0.008^{* * *} \\
(0.001)\end{array}$ & $\begin{array}{c}-0.013^{* * *} \\
(0.001)\end{array}$ \\
\hline Experience $^{2}$ & $\begin{array}{l}0.0001^{* *} \\
(0.0000)\end{array}$ & $\begin{array}{c}0.0002^{* * *} \\
0.00006\end{array}$ & $\begin{array}{l}0.0001^{* *} \\
(0.0000)\end{array}$ & $\begin{array}{c}0.0000 \\
(0.0000)\end{array}$ \\
\hline Tenure & $\begin{array}{c}-0.027^{* * *} \\
(0.002)\end{array}$ & $\begin{array}{c}-0.035^{* * *} \\
(0.002)\end{array}$ & $\begin{array}{c}-0.023^{* * *} \\
(0.001)\end{array}$ & $\begin{array}{c}-0.034^{* * *} \\
(0.001)\end{array}$ \\
\hline Tenure $^{2}$ & $\begin{array}{l}0.001^{* * *} \\
(0.0000)\end{array}$ & $\begin{array}{l}0.001^{* * *} \\
(0.0001)\end{array}$ & $\begin{array}{l}0.001^{* * *} \\
(0.0000)\end{array}$ & $\begin{array}{l}0.001^{* * *} \\
(0.0000)\end{array}$ \\
\hline Female & $\begin{array}{l}-0.005 \\
(0.006)\end{array}$ & $\begin{array}{l}-0.010 \\
(0.008)\end{array}$ & $\begin{array}{c}-0.010^{* * *} \\
(0.003)\end{array}$ & $\begin{array}{c}0.001 \\
(0.004)\end{array}$ \\
\hline Education - College & $\begin{array}{c}-0.071^{* * *} \\
(0.009)\end{array}$ & $\begin{array}{c}-0.081^{* * *} \\
(0.014)\end{array}$ & $\begin{array}{c}-0.041^{* * *} \\
(0.005)\end{array}$ & $\begin{array}{c}-0.053^{* * *} \\
(0.007)\end{array}$ \\
\hline Education - Vocational & $\begin{array}{c}-0.020 * * * \\
(0.006)\end{array}$ & $\begin{array}{c}-0.044^{* * *} \\
(0.008)\end{array}$ & $\begin{array}{c}-0.034^{* * *} \\
(0.003)\end{array}$ & $\begin{array}{c}-0.046^{* * *} \\
(0.004)\end{array}$ \\
\hline Education - Community & $\begin{array}{c}-0.043^{* * *} \\
(0.014)\end{array}$ & $\begin{array}{c}-0.065^{* * *} \\
(0.020)\end{array}$ & $\begin{array}{c}-0.057^{* * *} \\
(0.006)\end{array}$ & $\begin{array}{c}-0.092^{* * *} \\
(0.009)\end{array}$ \\
\hline Full time & $\begin{array}{c}-0.081^{* * *} \\
(0.006)\end{array}$ & $\begin{array}{c}-0.059 * * * \\
(0.008)\end{array}$ & $\begin{array}{c}-0.052^{* *} \\
(0.003)\end{array}$ & $\begin{array}{c}-0.052^{* * *} \\
(0.004)\end{array}$ \\
\hline Hourly wage (kroner) & $\begin{array}{c}0.0001^{* * *} \\
(0.0000)\end{array}$ & $\begin{array}{c}0.0001 \\
(0.0001)\end{array}$ & $\begin{array}{c}0.0001^{* * *} \\
(0.0000)\end{array}$ & $\begin{array}{c}0.0001^{* * *} \\
(0.0000)\end{array}$ \\
\hline Merger size & $\begin{array}{c}-0.0001^{* * *} \\
(0.0000) \\
\end{array}$ & $\begin{array}{c}-0.0000^{* * *} \\
(0.0000) \\
\end{array}$ & $\begin{array}{c}-0.0000^{* * *} \\
(0.0000) \\
\end{array}$ & $\begin{array}{c}-0.0000^{* * *} \\
(0.0000)\end{array}$ \\
\hline $\operatorname{LR} \chi^{2}$ & 2954.96 & 4565.90 & 9143.74 & 14766.36 \\
\hline Predicted probability & 0.22 & 0.51 & 0.17 & 0.41 \\
\hline $\mathrm{N}$ & & & & \\
\hline
\end{tabular}

Turnover and dominance are continuous variables scaled between 0 and 1. Marginal changes are reported instead of the coefficients. Standard errors are reported in parenthesis. ${ }^{* * *} /{ }^{* *} /{ }^{*}$ indicates significance is at $1 \% / 5 \% / 10 \%$ respectively. 
TABLE 7 - Post Merger Wage Growth (OLS estimation)

\begin{tabular}{|c|c|c|c|c|}
\hline \multirow{2}{*}{$\begin{array}{l}\text { Dept. Variable: } \\
\text { Post Merger Wage } \\
\text { Growth }\end{array}$} & \multicolumn{2}{|c|}{ Acquired Employees } & \multicolumn{2}{|c|}{ Acquirer Employees } \\
\hline & $\begin{array}{l}1 \text { year wage } \\
\text { growth }\end{array}$ & $\begin{array}{l}3 \text { years wage } \\
\text { growth }\end{array}$ & $\begin{array}{l}1 \text { year wage } \\
\text { growth }\end{array}$ & $\begin{array}{l}3 \text { years wage } \\
\text { growth }\end{array}$ \\
\hline Dominance of A over B & $\begin{array}{c}-0.043^{* * *} \\
(0.010)\end{array}$ & $\begin{array}{l}-0.028^{*} \\
(0.016)\end{array}$ & $\begin{array}{c}-0.028^{* * *} \\
(0.009)\end{array}$ & $\begin{array}{c}-0.008 \\
(0.010)\end{array}$ \\
\hline Industry Difference & $\begin{array}{c}-0.004 \\
(0.008)\end{array}$ & $\begin{array}{l}-0.005 \\
(0.013)\end{array}$ & $\begin{array}{l}0.0003 \\
(0.005)\end{array}$ & $\begin{array}{c}-0.017^{* * *} \\
(0.005)\end{array}$ \\
\hline Merger type 2 & $\begin{array}{c}0.010 \\
(0.008)\end{array}$ & $\begin{array}{l}-0.020 \\
(0.013)\end{array}$ & $\begin{array}{l}-0.007 \\
(0.006)\end{array}$ & $\begin{array}{c}-0.041^{* * *} \\
(0.007)\end{array}$ \\
\hline Merger type 3 & $\begin{array}{c}0.002 \\
(0.010)\end{array}$ & $\begin{array}{l}-0.005 \\
(0.015)\end{array}$ & $\begin{array}{l}0.0002 \\
(0.004)\end{array}$ & $\begin{array}{c}0.026^{* * *} \\
(0.004)\end{array}$ \\
\hline Constant & $\begin{array}{c}0.205^{* * *} \\
(0.033)\end{array}$ & $\begin{array}{c}1.231^{* * *} \\
(0.067)\end{array}$ & $\begin{array}{c}0.334^{* * *} \\
(0.019)\end{array}$ & $\begin{array}{l}1.130^{* * *} \\
(0.023)\end{array}$ \\
\hline Controls & \multicolumn{4}{|c|}{$\begin{array}{l}\text { Age, } \text { Age }^{2} \text {, Experience, Experience }{ }^{2} \text {, Tenure, Tenure }{ }^{2} \text {, Female, } \\
\text { Education Groups, Full time, Hourly wage, Merger size }\end{array}$} \\
\hline $\begin{array}{l}\text { Adjusted } \mathrm{R}^{2} \\
\mathrm{~N}\end{array}$ & $\begin{array}{c}0.06 \\
17,092\end{array}$ & $\begin{array}{c}0.14 \\
11,207\end{array}$ & $\begin{array}{c}0.04 \\
64,155\end{array}$ & $\begin{array}{c}0.21 \\
46,891\end{array}$ \\
\hline
\end{tabular}

Turnover and dominance are continuous variables scaled between 0 and 1 . Standard errors are reported in parenthesis. ${ }^{* * *} / * * / *$ indicates significance is at $1 \% / 5 \% / 10 \%$ respectively 
TABLE 8 - Post Merger Turnover - Clustered Standard Errors (Probit estimation)

\begin{tabular}{|c|c|c|c|c|}
\hline \multirow{2}{*}{$\begin{array}{l}\text { Dept. Variable: } \\
\text { Post Merger Turnover }\end{array}$} & \multicolumn{2}{|c|}{ Acquired Employees } & \multicolumn{2}{|c|}{ Acquirer Employees } \\
\hline & $\begin{array}{l}1 \text { year } \\
\text { turnover }\end{array}$ & $\begin{array}{l}3 \text { years } \\
\text { turnover }\end{array}$ & $\begin{array}{l}1 \text { year } \\
\text { turnover }\end{array}$ & $\begin{array}{l}3 \text { years } \\
\text { turnover }\end{array}$ \\
\hline Dominance of A over B & $\begin{array}{c}0.115^{* * *} \\
(0.040)\end{array}$ & $\begin{array}{c}0.299^{* * *} \\
(0.079)\end{array}$ & $\begin{array}{l}-0.005 \\
(0.036)\end{array}$ & $\begin{array}{l}-0.025 \\
(0.069)\end{array}$ \\
\hline Industry Difference & $\begin{array}{c}0.003 \\
(0.023)\end{array}$ & $\begin{array}{c}0.023 \\
(0.070)\end{array}$ & $\begin{array}{l}0.034 \\
(0.027)\end{array}$ & $\begin{array}{c}0.015 \\
(0.030)\end{array}$ \\
\hline Merger type 2 & $\begin{array}{l}-0.003 \\
(0.024)\end{array}$ & $\begin{array}{l}-0.023 \\
(0.050)\end{array}$ & $\begin{array}{c}0.009 \\
(0.022)\end{array}$ & $\begin{array}{c}0.028 \\
(0.037)\end{array}$ \\
\hline Merger type 3 & $\begin{array}{l}-0.017 \\
(0.023)\end{array}$ & $\begin{array}{l}-0.081^{* *} \\
(0.038)\end{array}$ & $\begin{array}{l}-0.026 \\
(0.019)\end{array}$ & $\begin{array}{l}-0.058 \\
(0.030)\end{array}$ \\
\hline Wald $\chi^{2}$ & 759.42 & 931.67 & 2779.60 & 2819.09 \\
\hline Predicted probability & 0.22 & 0.51 & 0.17 & 0.41 \\
\hline $\mathrm{N}$ & \multicolumn{2}{|c|}{22,662} & \multicolumn{2}{|c|}{80,405} \\
\hline Controls & \multicolumn{4}{|c|}{$\begin{array}{l}\text { Age, } \text { Age }^{2} \text {, Experience, Experience }{ }^{2} \text {, Tenure, Tenure }{ }^{2} \text {, Female, } \\
\text { Education Groups, Full time, Hourly wage, Merger size }\end{array}$} \\
\hline
\end{tabular}

Turnover and dominance are continuous variables scaled between 0 and 1. Marginal changes are reported instead of the coefficients. Robust standard errors adjusted for clusters at the merger year level are reported in parenthesis. ${ }^{* * *} /{ }^{* *} /{ }^{*}$ indicates significance is at $1 \% / 5 \% / 10 \%$ respectively 
FIGURE 1 - Post Merger Turnover and Dominance - Semi Parametric Estimation
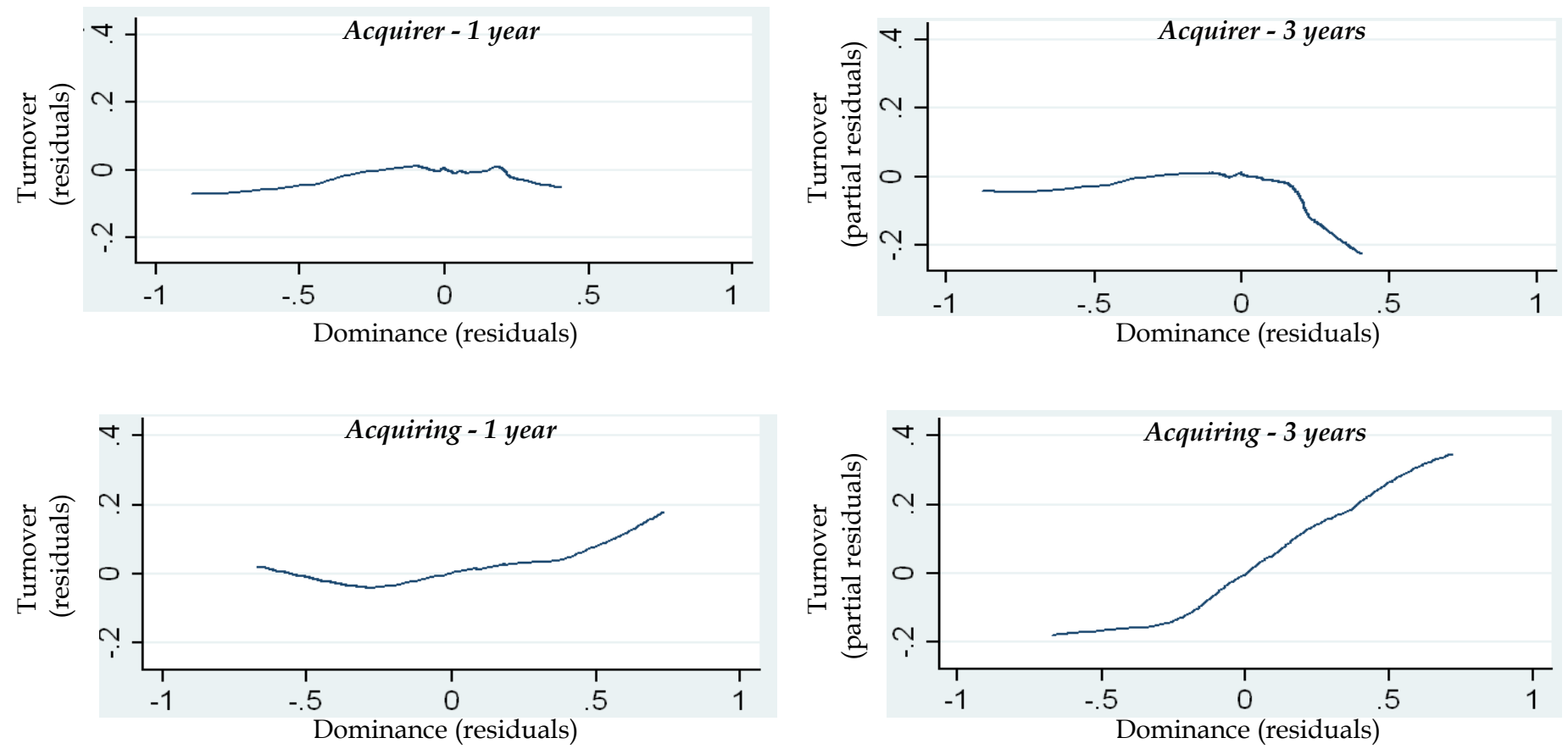

The lines in the figure are graphs of the standardized residuals of turnover, as a function of the residuals of dominance of the acquirer at the time of the merger. The upper panels graph the relationship for acquirer workers; the bottom for acquirer workers. Left is 1 year after the merger, while right is 3 years after the merger. The estimates are obtained from a semi-parametric estimation where control variables have been previously partialled-out as explained in the ext. The data are worker observations at the time of the merger. 